\title{
Electrochemical Corrosion Behaviour of Nano Aluminium - Polytetrafluoroethylene Pigment Modified Water borne Epoxy Coating on Carbon Steel
}

\author{
Mingshuai Guo ${ }^{1}$, Qingyang Zeng ${ }^{1}$, Xiaoting Ren ${ }^{1}$, Lili Xue ${ }^{1, *}$, Yonglei Xin ${ }^{2, *}$, Yueming Ren ${ }^{l}$, \\ Likun $\mathrm{Xu}^{2}, \mathrm{Li} \mathrm{Li}^{1}$ \\ ${ }^{1}$ Center for Biomedical Materials and Engineering, Institude of Materials Processing and Intelligent \\ Manufacturing, College of Materials Science and Chemical Engineering, Harbin Engineering \\ University, 145 Nantong Street, Harbin City, Heilongjiang Province, 150001, P.R. China \\ ${ }^{2}$ State Key Laboratory for Marine Corrosion and Protection, Luoyang Ship Material Research Institute \\ (LSMRI), Qingdao, 266237, P.R. China \\ *E-mail: xinyl@sunrui.net; xuelili@hrbeu.edu.cn
}

doi: $10.20964 / 2021.01 .37$

Received: 27 August 2020 / Accepted: 3 November 2020 / Published: 30 November 2020

For fasteners, corrosion causes rust on the threads, reduces their strength and making their disassembly difficult. The protective coating of fasteners needs to have excellent anti-corrosion and lubricating properties. In this paper, nano Aluminium (nano-Al) and Polytetrafluoroethylene (PTFE) particles were used to fabricate a nano Al-PTFE epoxy self-stratifying structure coating. The SEM, AFM, and DSC results show that the coating formed a self-stratifying structure when it is pre-dried at $110^{\circ} \mathrm{C}$ and then dried at $200^{\circ} \mathrm{C}$. PTFE is located on the surface of the coating to enhance lubricity, while nano-Al is located at the bottom of the coating to enhance corrosion resistance. Moreover, Electrochemical impedance spectroscopy (EIS) shows that the $\mathrm{C}_{\mathrm{dl}}$ of the nano Al-PTFE modified coating with an artificial defect is lower, while its $R_{c t}$ is higher than that of the other two coatings, indicating that corrosive electrochemical activity only occurred in a small area of the coating. The SVET results indicate that the distance of the nano Al-PTFE modified coating from the defect edge contour only changed a little after $48 \mathrm{~h}$ of immersion. In conclusion, the coating has good anti-corrosion performance.

Keywords: Corrosion behaviour; Nano Al-PTFE; Self-stratifying; EIS; SVET

\section{$\underline{\text { FULL TEXT }}$}

(C) 2021 The Authors. Published by ESG (www.electrochemsci.org). This article is an open access article distributed under the terms and conditions of the Creative Commons Attribution license (http://crea tivecommons.org/licenses/by/4.0/). 